\title{
A Case of Hypocalcaemia Due to Vitamin D Deficiency in 'Hikikomori' Syndrome
}

\author{
Takahiro Miyakoshi ${ }^{1}$, Mamoru Satoh ${ }^{2}$, Fumio Nomura ${ }^{2}$, Takao Hashimoto $^{3}$, Toru Aizawa $^{3}$ \\ ${ }^{1}$ Diabetes Center, Department of Neurology, Aizawa Hospital, Matsumoto, Japan \\ ${ }^{2}$ Division of Clinical Mass Spectrometry, Chiba University Hospital, Chiba, Japan \\ ${ }^{3}$ Department of Neurology, Aizawa Hospital, Matsumoto, Japan
}

Received: 14/05/2017

Accepted: 07/06/2017

Published: $19 / 06 / 2017$

How to cite this article: Miyakoshi T, Satoh M, Nomura F, Hashimoto T, Aizawa T. A case of hypocalcaemia due to vitamin D deficiency in 'Hikikomori" syndrome. EJCRIM 2017;4: doi:10.12890/2017_000634.

Conflicts of Interests: The Authors declare that there are no competing interests.

Acknowledgements: The authors thank Drs. Tadashi Doden, Masaki Kakizawa, Osamu Taga, Takayuki Ishige, Yasuto Nakasone, Yuka Sato, Naokazu Yokota, Koh Yamashita, Keishi Yamauchi and Kiyoshi Tanaka for their invaluable comments.

This article is licensed under a Commons Attribution Non-Commercial 4.0 License

\section{ABSTRACT}

Objective: To describe hypocalcaemia due to vitamin D deficiency in 'hikikomori' syndrome.

Materials and methods: A 37-year-old man with 'hikikomori' syndrome for a year was admitted with hypocalcaemia (serum ionic calcium 1.17 $\mathrm{mmol} / \mathrm{l})$. Serum $1,25(\mathrm{OH})_{2}$-vitamin $\mathrm{D}_{3}$ determined by liquid chromatography-tandem mass spectrometry was depressed at $12.1 \mathrm{pg} / \mathrm{ml}(29.0$ pmol/l) and plasma intact PTH elevated at $324 \mathrm{ng} / \mathrm{l}$. Administration of $1 \mathrm{\mu g} / \mathrm{day} 1 \mathrm{\alpha}(\mathrm{OH})$-vitamin $\mathrm{D}_{3}$ and $1 \mathrm{~g} /$ day calcium lactate for $1 \mathrm{week}$ normalized calcium and PTH, and raised $1,25(\mathrm{OH})_{2}$-vitamin $\mathrm{D}_{3}$ to low normal levels.

Conclusion: This is the first report of hypocalcaemia due to vitamin D deficiency in a patient with 'hikikomori' syndrome.

\section{LEARNING POINTS}

- A patient with psychiatric disorders can develop endocrine/metabolic abnormality.

- Hikikomori syndrome should be listed as a possible cause of hypocalcaemia in adults.

- Early diagnosis of hypocalcaemia in hikikomori syndrome prevents bone damage.

\section{KEYWORDS}

Hikikomori syndrome, Hypocalcaemia, Hypovitaminosis D

\section{CASE DESCRIPTION}

'Hikikomori' syndrome has been described as complete withdrawal from society for 6 months or longer ${ }^{[1]}$. In the English version of Oxford Dictionaries, hikikomori is defined as (in Japan) the abnormal avoidance of social contact, typically by adolescent males. A person who avoids social contact. Origin: Japanese. literally "staying indoors, (social) withdrawal". There are almost 1 million hikikomori in Japan between the ages of 20 and 40. Hikikomori syndrome ${ }^{[1,2]}$ is regarded as a mental or psychiatric disorder and most probably for this reason, metabolic abnormality, in particular hypocalcaemia, associated with this condition has not been described. 
A 37-year-old man was admitted due to hypothermia and bizarre behaviour in mid-winter. He was found by his family unresponsive to verbal stimuli with rectal incontinence in his room without clothing or heating: the room temperature was $10^{\circ} \mathrm{C}$. He had lived with his parents for about a year but rarely left his room, except for an occasional short walk at night. His past and family history was otherwise unremarkable except for his mother's hypertension.

Upon admission, his rectal temperature was $30.9^{\circ} \mathrm{C}$, consciousness was Glasgow Coma Scale 3 (E1V1M1), blood pressure was $84 / 46 \mathrm{mmHg}$ and pulse rate was $72 / \mathrm{min}$, regular. His BMI was $20.5 \mathrm{~kg} / \mathrm{m}^{2}$. There was generalized muscle weakness but Chvostek's and Trousseau's signs were negative. The patient had hypocalcaemia, as shown by an albumin-corrected serum calcium concentration (CSC) of $1.6 \mathrm{mmol} / \mathrm{I}$, ionic calcium of $1.17 \mathrm{mmol} / \mathrm{l}$ (reference range, 1.21-1.36) and low urinary excretion of calcium of $0.009 \mathrm{mg} / \mathrm{g}$ creatinine (Table 1). ECG showed normal sinus rhythm and QTc was within the normal range at $0.416 \mathrm{sec}$. He also had hypoglycaemia, hypernatraemia and hyperkalaemia. Serum levels of hepatic enzymes except for YGTP were elevated; the serum alcohol concentration was not elevated. Renal function was also impaired (Table 1). Serum levels of vitamin $B_{12}$ and folic acid were normal. Treatment with fluid and external warming was instituted, and the patient's body temperature rose to $36.5^{\circ} \mathrm{C}$ within 6 hours and consciousness was normalized by day 2 . Hypocalcaemia was investigated further.

\begin{tabular}{|c|c|c|c|c|c|}
\hline & Day 0 & Day 2 & Day 8 & Day 15 & Day 45 \\
\hline \multicolumn{6}{|l|}{ Serum chemistry } \\
\hline Total protein, g/dl (6.7-8.3) & 8.0 & & 5.7 & & 6.6 \\
\hline Albumin, g/dl (3.8-5.1) & 4.9 & & 3.0 & 2.7 & 3.0 \\
\hline Calcium, mg/dl (8.5-10.9) & 7.1 & 6.4 & 8.3 & 8.8 & \\
\hline $\mathrm{CSC}, \mathrm{mg} / \mathrm{dl}$ & 6.2 & & 9.3 & 10.1 & \\
\hline Ionic calcium, mmol/I (1.21-1.36) & & 1.17 & & & \\
\hline Phosphate, mg/dl (2.5-4.5) & & 4.7 & 4.4 & 4.9 & \\
\hline Intact PTH, pg/ml (10-65) & & 324 & & 30 & \\
\hline AST, IU/I (11-39) & 475 & 589 & 51 & 44 & 17 \\
\hline ALT, IU/I (5-43) & 126 & 124 & 27 & 22 & 10 \\
\hline yGTP, IU/I (10-80) & 28 & 17 & 36 & 63 & 28 \\
\hline LDH, IU/I (115-245) & 664 & 1903 & 399 & 283 & 189 \\
\hline ALP, IU/I (105-320) & 295 & 192 & 196 & 240 & 201 \\
\hline BUN, mg/dl (8-20) & 46.0 & 41.3 & 10.6 & 8.3 & 8.6 \\
\hline $\mathrm{Na}, \mathrm{mEq} / \mathrm{l}(135-147)$ & 149 & 139 & 138 & 138 & 140 \\
\hline $\mathrm{K}, \mathrm{mEq} / \mathrm{I}(3.4-4.8)$ & 5.2 & 4.5 & 4.2 & 4.8 & 4.2 \\
\hline Scr, mg/dl (0.4-0.7) & 3.53 & 2.9 & 0.74 & 0.72 & 0.69 \\
\hline eGFR, ml/min/1.73 m2 & 17.32 & 23.4 & 95.7 & 98.5 & 103.3 \\
\hline Alcohol, $\mathrm{mg} / \mathrm{ml}$ & $<0.1$ & & & & \\
\hline Bone ALP, $\mu \mathrm{g} / \mathrm{l}(3.7-20.9)$ & & 7.7 & & & \\
\hline NTX, nmol BCE/l & & 71.2 & & & \\
\hline Random glucose, mg/dl & 12 & 131 & 112 & 90 & 111 \\
\hline Insulin, $\mu \mathrm{U} / \mathrm{ml}$ & & 8.2 & & & \\
\hline $\mathrm{HbA} 1 \mathrm{c}, \%$ & & 4.8 & & & \\
\hline Vitamin $B_{12}, \mathrm{pg} / \mathrm{ml}(180-914)$ & & 885 & & & \\
\hline Folic acid, $\mathrm{ng} / \mathrm{ml}(\geq 4.0)$ & & 5.2 & & & \\
\hline \multicolumn{6}{|l|}{ Urine chemistry } \\
\hline $\mathrm{Ca}, \mathrm{mg} / \mathrm{g}$ creatinine & 8.5 & & & 1.9 & \\
\hline Phosphate, mg/dl & 28.7 & & & 2.9 & \\
\hline Creatinine, $\mathrm{mg} / \mathrm{dl}$ & 35.0 & & & 42.0 & \\
\hline \%TRP & 38.4 & & & 99 & \\
\hline
\end{tabular}

Table 1. General laboratory data

$A L P$, alkaline phosphatase; ALT, alanine aminotransferase; AST, aspartate aminotransferase; $B C E / I, n m o l$ bone collagen equivalents/l; BUN, blood urea nitrogen; CSC, albumin-corrected serum calcium; VGTP, gamma-glutamyl transpeptidase; eGFR, estimated glomerular filtration rate; $L D H$, lactate dehydrogenase; NTX, collagen type 1 cross-linked N-telopeptide; PTH, parathyroid hormone; Scr, serum creatinine; \%TRP, percent tubular reabsorption of phosphate.

Medications are described in the footnote of Table 2. 
Initially, determination of 25(OH)-vitamin $\mathrm{D}\left(\mathrm{D}_{2}\right.$ and $\mathrm{D}_{3}$ combined) (Diasorin, Stillwater, $\left.\mathrm{MN}\right), 1,25(\mathrm{OH})_{2}$-vitamin $\mathrm{D}_{3}$ (Immunodiagnostic Systems, Gaithersburg, MD) by radioimmunoassay (RIA) and intact parathyroid hormone (PTH) by electrochemiluminescence assay (Elecsys, Roche, Basel, Switzerland) was carried out at Special Reference Laboratories, Tokyo. Upon receiving an unexpectedly normal value for $1,25(\mathrm{OH})_{2}$-vitamin $\mathrm{D}_{3}$ (Table 2), serum levels of vitamin $\mathrm{D}$ and related molecules were re-determined by liquid chromatography-tandem mass spectrometry (LC-MS/MS) ${ }^{[3-5]}$.

Serum concentrations of vitamin D and its precursors and metabolites are shown in Table 2. LC-MS/MS indicated that levels of vitamin D and its precursors and metabolites were all depressed, particularly $1,25(\mathrm{OH})_{2}$-vitamin $\mathrm{D}_{3}$. It should be noted that the values obtained by RIA for $25(\mathrm{OH})$-vitamin $D\left(D_{2}\right.$ and $D_{3}$ combined) and $1,25(\mathrm{OH})_{2}$-vitamin $D_{3}$ were within the reference range. The plasma level of intact PTH was markedly elevated and urinary excretion of phosphate was elevated as indicated by low tubular reabsorption of phosphate. Bone alkaline phosphatase and collagen type 1 cross-linked N-telopeptide (NTX) were within the reference range (Table 2).

\begin{tabular}{|c|c|c|c|c|}
\hline & Day 2 & Day 8 & Day 38 & Day 45 \\
\hline \multicolumn{5}{|l|}{ LC-MS/MS } \\
\hline $25(\mathrm{OH})$-vitamin $\mathrm{D}_{2}, \mathrm{ng} / \mathrm{ml}$ & 0.29 & 0.32 & & 0.10 \\
\hline $25(\mathrm{OH})$-vitamin $\mathrm{D}_{3}, \mathrm{ng} / \mathrm{ml}$ & 4.49 & 4.45 & & 5.49 \\
\hline 1,25(OH)2-vitamin $\mathrm{D}_{3}, \mathrm{pg} / \mathrm{ml}$ & 12.1 & 10.6 & & 27.1 \\
\hline 3-epi-25(OH)-vitamin $\mathrm{D}_{3}$, ng/ml & 0.33 & 0.33 & & 0.24 \\
\hline $24,25(\mathrm{OH})_{2}$-vitamin $\mathrm{D}_{3}, \mathrm{ng} / \mathrm{ml}$ & 0.19 & 0.21 & & 0.27 \\
\hline $1,25(\mathrm{OH})_{2}$-vitamin $\mathrm{D}_{2}, \mathrm{pg} / \mathrm{ml}$ & $<1.8$ & $<1.8$ & & $<1.8$ \\
\hline \multicolumn{5}{|l|}{ Radioimmunoassay } \\
\hline $25(\mathrm{OH})$-vitamin $\mathrm{D}\left(\mathrm{D}_{2}\right.$ and $\mathrm{D}_{3}$ combined $), \mathrm{ng} / \mathrm{ml}$ & 8.0 & & 8.0 & \\
\hline $1,25(\mathrm{OH})_{2}$-vitamin $\mathrm{D}_{3}, \mathrm{pg} / \mathrm{ml}$ & 38.4 & & 24.4 & \\
\hline
\end{tabular}

Table 2. Serum levels of vitamin D and related substances before and after treatment

LC-MS/MS, liquid chromatography-tandem mass spectrometry. Medications were as follows. $1 \alpha(\mathrm{OH})$-Vitamin $\mathrm{D}_{3}: 1 \mu \mathrm{g} /$ day from day 2 to day $15,0.5 \mu \mathrm{g} /$ day from day 16 to day 17 , withdrawn from day 18 to day $41,0.25 \mu \mathrm{g} /$ day from day 42 , and on. Calcium lactate: 1 $\mathrm{g} /$ day from day 2 to day 10 , withdrawn from day 11 to day $34,1 \mathrm{~g} /$ day from day 35 , and so on. Calcium carbonate: $1 \mathrm{~g} /$ day from day 11 to day 34

Hypocalcaemia was diagnosed as caused by vitamin D deficiency arising from insufficient ultraviolet B irradiation due to hikikomori syndrome. Oral administration of $1 \mu \mathrm{g} / \mathrm{day} 1 \mathrm{a}(\mathrm{OH})$-vitamin $\mathrm{D}_{3}$ and $1 \mathrm{~g} /$ day calcium lactate was begun. Treatment raised serum calcium levels within a week and normalized plasma intact PTH within 15 days (Table 2). At the same time, generalized muscle weakness disappeared. The plasma $1,25(\mathrm{OH})_{2}$-vitamin $\mathrm{D}_{3}$ level remained low at this stage but rose to the low normal range by day 45 .

\section{DISCUSSION}

Vitamin D deficiency in adults is not uncommon and frequently due to inadequate exposure to sunlight. Because of prolonged social withdrawal, patients with hikikomori syndrome may develop vitamin D deficiency due to inadequate exposure to sunlight. Nonetheless, hypocalcaemia and/or vitamin D deficiency has not previously been reported in hikikomori syndrome ${ }^{[1,2]}$ and may have been overlooked. In fact, Chvostek's and/or Trousseau's signs were both negative in this case, and hypocalcaemia was found incidentally during the general laboratory investigation. The lifestyle of this patient was typical of 'hikikomori' syndrome in that he had no exposure to sunlight for about a year. Consequently, the pathophysiology of this patient was similar to rickets. Nonetheless, bone alkaline phosphatase and NTX were normal, indicating that bone turnover had not yet been depressed.

Importantly, the RIA method commonly used to assess vitamin D and related molecules may not be reliable when levels are very low, as in this patient, since RIA overestimated vitamin D and a precursor molecule, as reported elsewhere. Therefore, RIA should not be relied on solely to diagnose vitamin D deficiency, with LC-MS/MS being a better choice ${ }^{[3-5]}$.

In conclusion, we have described hypocalcaemia in 'hikikomori' syndrome arising vitamin D deficiency for the first time. Further studies are warranted to establish the prevalence and severity of hypocalcaemia and vitamin D deficiency in this syndrome. LC-MS/MS instead of RIA is recommended as the method to determine levels of vitamin D and its metabolites in order to assess vitamin D levels. 


\section{REFERENCES}

1. Watts J. Public health experts concerned about "hikikomori". Lancet 2002;359:1131.

2. Kato TA, Tateno M, Shinfuku N, et al. Does the 'hikikomori' syndrome of social withdrawal exist outside Japan? A preliminary international investigation. Soc Psychiatry Psychiatr Epidemiol 2012;47:1061-1075.

3. Herrmann M, Farrell CL, Pusceddu I, Fabregat-Cabello N, Cavalier E. Assessment of vitamin D status - a changing landscape. Clin Chem Lab Med 2016;55:3-26.

4. Mochizuki A, Kodera Y, Saito T, et al. Preanalytical evaluation of serum 25-hydroxyvitamin D3 and 25-hydroxyvitamin D2 measurements using LC-MS/MS. Clin Chim Acta 2013;420:114-120.

5. Satoh M, Ishige T, Ogawa S, et al. Development and validation of the simultaneous measurement of four vitamin D metabolites in serum by LC-MS/MS for clinical laboratory applications. Anal Bioanal Chem 2016;408:7617-7627. 